\title{
Good global dental health
}

The BDA attended the FDI World Dental Congress 2018 in Buenos Aires from 5 to 8 September 2018.

The FDI World Dental Congress brings together dental representatives from across the world to discuss policy and advocacy issues with the aim to lead the world to better dental health.

BDA Chair Mick Armstrong was elected to the Dental Practice Committee and Professor David Williams was re-elected to the Science Committee. Both join BDA President Susie Sanderson who was elected to the role of Speaker of the FDI General Assembly in 2017, and who led delegates through a week of meetings and discussions.

Apart from elections to committees, the FDI Congress saw the adoption of ten new or revised policy statements ${ }^{1}$ on:

- (Deep) Dentine Caries and Restorative Care

- Continuing Medical Education in Dentistry

- Dental Amalgam Phase-Down

- Dentistry and Oral Health-Related Apps

- Dentistry and Sleep-Related Breathing Disorders

- Global Periodontal Health

- Nanoparticles in Dental Practice

- National Health Policy

- Promoting Oral Health through Fluoride Toothpaste

- Providing Basic Oral Healthcare for Displaced Persons

The second edition of the FDI's Dental Ethics manual ${ }^{2}$ was also launched at the Congress.

The World Oral Health Forum (WOHF), an annual in-depth session on a specific topic that takes place at the Congress, focused on oral health and healthy ageing.

An advocacy leaflet, Achieving a healthy ageing society, ${ }^{3}$ was released, emphasising the need to adapt health systems to meet the increasing oral health needs of ageing populations worldwide.

Also available is a Roadmap for Healthy Ageing, ${ }^{3}$ a quick reference guide outlining strategies and actions that stakeholders can implement to address the oral health needs of older adults. The publication was developed by FDI's Oral Health for an Ageing Population (OHAP) Task Team.

Another significant session at the Congress was 'Curbing the Sugar Rush: Tackling oral diseases and other NCDs through a unified approach' - a joint meeting by the FDI, the NCD Alliance and the WHO (World Health Organisation).

The meeting focused on the advocacy work of oral health organisations to highlight that most oral diseases are preventable and com-

mitments from governments are needed to address the sugar content in food and drink products to combat a wide range of non-communicable diseases which all have

the same risk factors.
The FDI General Assembly received
updates on the following projects - Vision 2020: Minimum Oral Health Standard Set; World Oral Health Day; International Dental Journal; World Dental Development Fund; Continuing Education Programme; Oral Health Observatory; Endodontics; Caries Prevention Partnership; Peri Implant Disease Project; Brush Day and Night

Partnership; Global Periodontal Health Project; Oral Cancer Project; and Smile Around the World.

In addition, the BDA delegation attended the Plenary Session of the FDI's European Regional Organisation, which considered a report from the Spanish Dental Association on the collapse of a dental chain and the ramifications for patients and the profession.

By Ulrike Matthesius

1. FDI. Policy statements. Available at https://www.fdiworlddental.org/resources/policy-statements (accessed December 2018).

2. FDI World Dental Federation. Dental Ethics Manual 2. 2018. Available at https://www. fdiworlddental.org/resources/manuals/dental-ethics-manual-2 (accessed December 2018).

3. FDI World Dental Federation. Achieving a healthy ageing society \& Roadmap for Healthy Ageing. 2018. Available at https://www.fdiworlddental.org/news/20180905/ advocacy-leaflet-and-roadmap-for-healthy-ageing-released-at-2018-world-oral-health (accessed December 2018).

\section{TV opportunity for dentists}

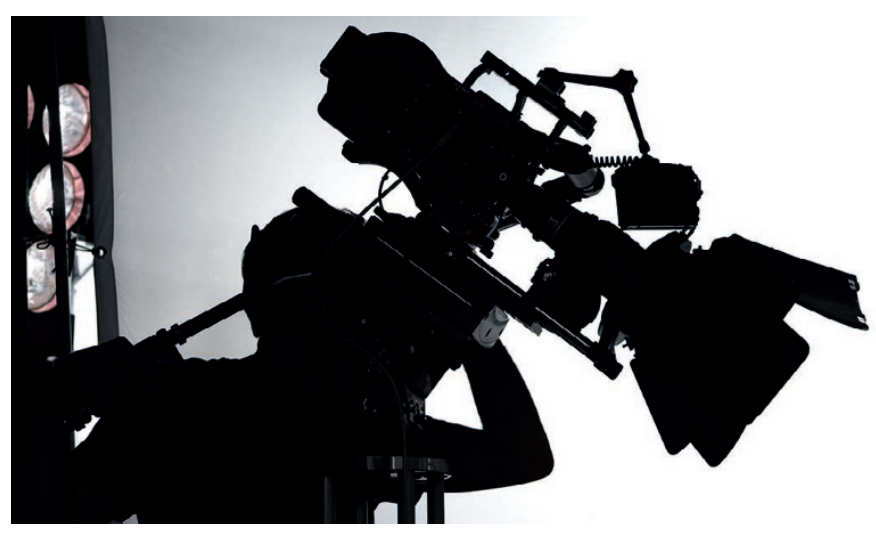

Dentists are being invited to apply to become part of a new television programme all about dentistry.

Elephant House Studios, a BAFTA award winning, in-house production company for Viacom, are seeking dentists for a new series for a major broadcaster. The company has previously produced what it describes as high-quality, warm-hearted programmes such as Cruising With Jane McDonald and the documentary Secrets of the Chocolate Factory: Inside Cadbury.

The company is looking for 25-45-year-olds from various backgrounds, all around the UK who would like to be on TV.

Anyone who is interested should email casting@elephanthousestudios.com. 